Physics Vol. 1, No. 5, p. 249, 1965. Physics Publishing Co. Printed in Great Britain.

\title{
EDITORIAL NOTE
}

The following short paper was written nearly ten years ago. At that time the author inquired widely whether this simple and useful mathematical result had not been previously derived, and it was discovered that Zener [1] had found it in a discussion, in 1932, of the potential curves of diatomic molecules. For that reason the paper was never published. Unfortunately, physicists continue to rederive this result, the latest example, to my knowledge, being C.B. Duke and W. Harrison (Proceedings of the Eastern Theoretical Physics Conference, College Park, Maryland, October 10, 1964). It is so simple and so generally useful that it seemed worth our while to publish the original paper, with appropriate apologies to Zener, Harrison and Duke, and any others who may have independently arrived at the same formula. This decision represents perhaps the first time in history a reprint of a preprint has been issued in the absence of the intermediate stage. A short paper by Upadhyaya [2], a collaborator of Wannier's, is very similar to that of Duke and gives one of the many applications; others occur in Zener's original field of molecular energy levels and atomic transitions in collisions, the theory of Bloch 'passages' in magnetic resonance spectroscopy, the theory of waveguide couplers [3], and of course, electric breakdown also.

1. C. ZENER, Proc. Roy. Soc. A137, 696 (1932).

2. U.N. UPADHYAYA, ONR Contract NONR 2771(05), Technical Report No. 4.

3. J.S. COOK, B.S.T.J. 34, 807 (1955) and following articles. 